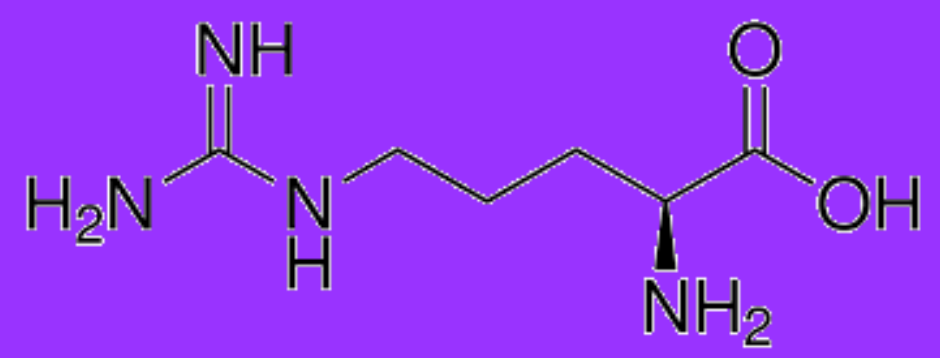

BJP
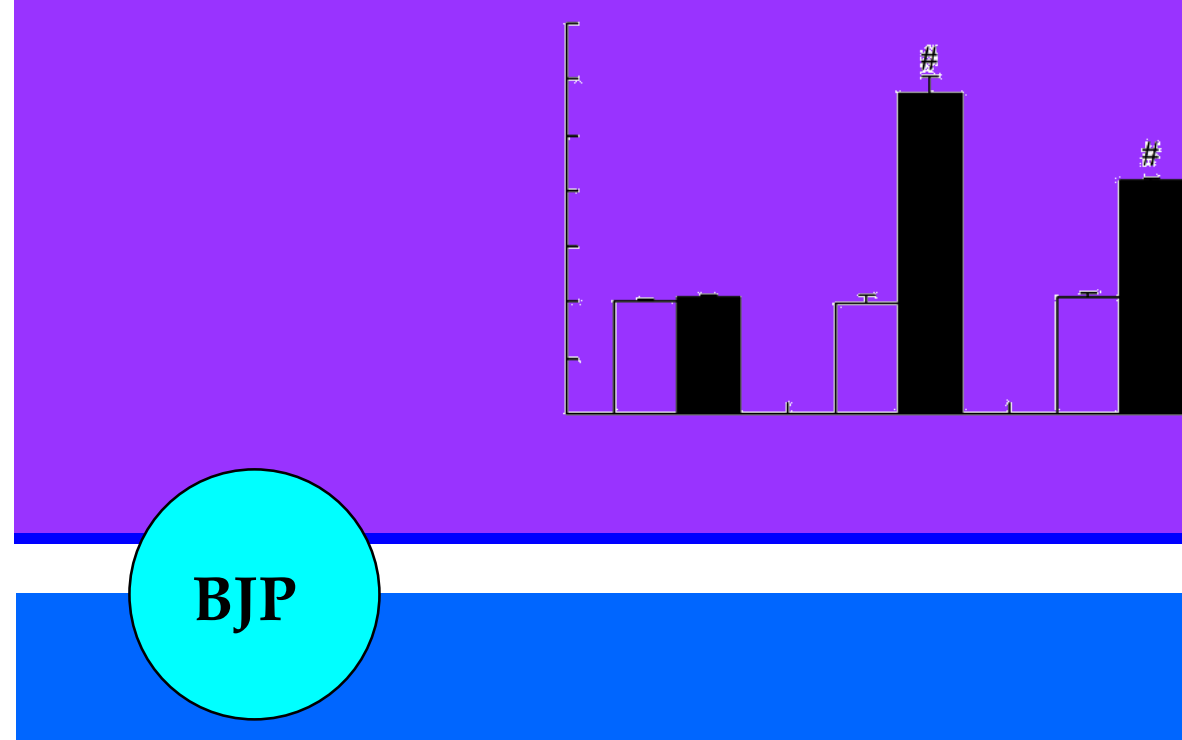

Bangladesh Journal of Pharmacology

Clinical Trial

Effect of intravenous arginine on the healing of human skin graft donar sites: A randomized controlled trial 


\section{Effect of intravenous arginine on the healing of human skin graft donor sites: A randomized controlled trial}

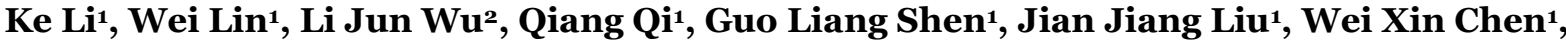 Jun Xu' ${ }^{1}$ Hangen Qian' and Xiao Yu Zhao'}

${ }^{1}$ Department of Plastic and Burn Surgery, The First Affiliated Hospital of Soochow University, Suzhou, Jiangsu 215 006, China; 'Department of Plastic Surgery, The Second Affiliated Hospital of Soochow University, Suzhou, Jiangsu 215 004, China.

\begin{tabular}{|lr|}
\hline Article Info \\
\hline Received: & 24 June 2015 \\
Accepted: & 17 July 2015 \\
Available Online: & 18 September 2015 \\
DOI: $10.3329 /$ bjp.v10i4.23850 \\
Cite this article: \\
Li K, Lin W, Wu LJ, Qi Q, Shen GL, \\
Liu JJ, Chen W, Xu J, Qian H, Zhao X. \\
Effect of intravenous arginine on the \\
healing of human skin graft donor \\
sites: A randomized controlled trial. \\
Bangladesh J Pharmacol. 2015; 10: 739 \\
-44.
\end{tabular}

\begin{abstract}
We expounded the effect of intravenous arginine on the healing of human skin graft donor sites. This randomized study was double blind and controlled by placebos from October 2012 to May 2015. Nine patients were selected into the arginine group and 10 were selected into the control group. There was no significance in age, weight, BMI, CRP, albumin and total plasma protein in arginine and control groups. Angiogenesis, re-epithelialization and neutrophil influx of wound healing were measured. The concentrations of plasma amino acid were measured to evaluate our intervention. In our study, plasma arginine and ornithine concentrations in arginine group were the highest after arginine-treated at 2 days. Supplementation of intravenous arginine could not affect on healing of human skin graft donor sites, improve angiogenesis, reepithelialization or neutrophil influx in rats.
\end{abstract}

\section{Introduction}

In the field of organ transplantation, induction of donor specific transplantation tolerance is still the ultimate goal of researchers and clinicians. It is an important means to increase the survival time of grafts and to eliminate various toxic and side effects caused by taking immunosuppressant for a long time (Lindford et al., 2011). However, so far, although there developed various methods of tolerance induction in animal studies, there is almost no scheme of tolerance induction which could be used clinically. Thus, to seek a new method or scheme of tolerance induction will help solve the many problems that organ transplantation is facing.

The barrier functions of skin tissue mainly embodies in two aspects: on one hand, it is to prevent the internal milieu disorder caused by the loss of internal water in the body, electrolyte and other substances; on the other hand, it is to prevent the body from invasion of various toxic substances (Roche-Kubler et al., 2015; Takabayashi et al., 2015). Many factors, such as large area deep burn, trauma, chronic ulcer, and some operations including congenital malformation operation and tumor resection often cause skin defects, which needs adequate skin to cover the wound to promote wound repair (Raza et al., 2014). Skin wound healing is a complex and highly coordinated process, during this process, wound covering has important significance. It can promote wound repair and prevent infection (Greenwood and Dearman, 2012). Skin graft is the popular method of treatment for traumatic and burns and for skin and tissue defects caused by other factors, and it's the most common operation in plastic surgery and burns surgery (Read and Bach, 1980).

As an important component of surgical nutrition, arginine may improve the nutritional support (Yurkiv et al., 2015). The current researches on the relationship between arginine and growth of xenografted tumor have no unified conclusion with the observation for phenomenon (Wu et al., 2014). Some researches indicate 
that arginine has antitumor effect, while others think arginine could promote tumor growth; and if the antitumor effect exists, the mechanism is still inconclusive (Nakase et al., 2012).

\section{Materials and Methods \\ Design and subjects}

Our department conducted a randomized study that was double blind and controlled by placebos from October 2012 to May 2015. The sample size for this study, built on average healing time of donor sites of 10 days, was determined and computed with confidence of $80 \%$ and accepting an a $5 \% .19$ participants from each group were to be included so as to discover an additional healing of $15 \%$. Each and every participant underwent skin autografting as an integral part of reconstructive surgery. Within half a year before surgery, a measurement of body mass index and weight loss was taken in order to decide upon the status of clinical nutrition in accordance with the principles. Criteria for enlisting participants consisted of the following: aged between 16 and 75, no kidney or liver failure, no pregnancy, non-use of steroids, no immune deficiency diseases, and no diabetes mellitus. Prior to an operation each of the participants was assigned at random to either of arginine $(n=9)$ and placebo treatment $(n=10)$ groups, by an independent clinical pharmacist, with the help of numbered envelopes. A block randomization was selected to equally divide subjects in both groups. On the basis of literature at the commencement of the study, the maximum amount of arginine that was tolerable was administered. All participants were given additional arginine or placebo intravenously (Bufa, Netherlands) over the course of 5 days, starting during surgery, so as to make an evaluation of the different processes during the beginning stages of wound healing (inflammatory and proliferative phase). The supplementation given intravenously included either a dose of $30 \mathrm{~g}$ of arginine every day, dissolved in $1000 \mathrm{~mL} 0.9 \% \mathrm{NaCl}$ and adjusted to $\mathrm{pH} 7.2$ using 10\% HCL (net nitrogen intake $45.7 \mathrm{mmol} / \mathrm{L}$ ) or a placebo treatment composed of a dose of $25.2 \mathrm{~g}$ of alanine every day, dissolved in $1000 \mathrm{ml}$ $0.9 \% \mathrm{NaCl}$ (net nitrogen intake $44 \mathrm{mmol} / \mathrm{L}$ ). With a view to undertaking a double-blind study the infusions were rendered isovolumetric and isonitrogenous. Despite the unlikelihood of turning them isocaloric, the arginine infusion made up $120 \mathrm{kcal}$ and the placebo infusion $100.8 \mathrm{kcal}$. Nevertheless, on a metabolic stress occasion, these differences are very small and thus oftentimes overlooked. Patients were provided with an infusion of $1000 \mathrm{~mL}$ every day in two doses of $500 \mathrm{ml}$ equally spaced out during the daytime. Oral intake of food was permitted if need be, so as to ensure the clinical employment of arginine as a possible immunonutrient treatment.

\section{Wound model}

All clinical wound procedures were performed at the Department of Plastic Surgery, University Hospital Maastricht, The Netherlands. Split skin grafts were made available with the assistance of an electric dermatome with a thickness of $0.3 \mathrm{~mm}$ under general anesthesia and aseptic conditions. The donor sites were made use of for the purpose of evaluating wound healing. The fluid of the wound was garnered at the donor sites by spreading a layer of Gordasoft on it initially and followed by a polyvinyl alcohol sponge and a see-through dressing at the top afterwards, as depicted above.

\section{Measurement of the surfaces of all donor sites}

Twenty-four hours prior to collection of wound fluid there was a change of the wound dressing by removing the transparent dressing and the sponge, followed by reapplying a new sponge and see-through dressing. 24 hours afterwards removal of the sponge took place, and it was stored on ice until further processing. By means of this protocol a wound fluid sample for 24 hours was made use of each time for analysis. Wound fluid samples were taken from each patient by employing this method on day 2, 5 and 10 respectively. 3-mm punch biopsies were taken from the central part of the donor site. Before the biopsies were excised, lidocaine was locally injected. At a subsequent time a venous blood sample was taken from a major vein in the cubital fossa.

\section{Sample gather}

Blood was centrifuged at $4,000 \mathrm{rpm}$ at $4^{\circ} \mathrm{C}$ for $10 \mathrm{~min}$ and stored at $-80^{\circ} \mathrm{C}$ until analysis. After centrifugation, dry sulphosalicylic acid (20 mg) was vortexed and liquid nitrogen were added into $500 \mathrm{~mL}$ of plasma and deproteinized. Wound fluid was also centrifuged at $11,000 \mathrm{rpm}$ at $4^{\circ} \mathrm{C}$ for $10 \mathrm{~min}$ and then was treated similar to the plasma. The recovery of fluid from the sponges was validated and found to be constant.

\section{Evaluation of wound healing}

2, 5 and 10 days post-surgery were chosen to reflect the inflammatory phase at 2 days, the proliferative phase at 5 days and re-epithelialization at 10 days. Biopsies firstly were fixed in $4 \%$ formaldehyde, then processed and embedded in paraffin. Biopsies sections fixed were subsequently obtained using a microscope (Nikon Eclipse 80i microscope, USA).

\section{Sections stained with hematoxylin and eosin}

In wound biopsies sections, polymorphonuclear neutronphils (PMNs) were defined as per high power field (HPF) at 40 of magnification at 2, 5 and 10 days post-surgery. Micro-vessel density (MVD) of wound biopsies was also measured at 2, 5 and 10 days post-surgery as described by (Baeten et al., 2002). Immunolabeling of mouse-anti-human alpha smooth muscle actin (Beast- 
Bio, China) and mouse-anti-human CD31 (Beast Bio, China) were used to stain vessels in the sections. Two independent investigators were measured using a microscope (Nikon Eclipse 80i microscope, USA).

\section{Re-epithelialization}

The image of the donor sites were measured with Canon EOS 300 and analyzed on days 5 and 10. Two blinded independent observers used morphometric program ImageJ to measure the planimetry surface of re -epithelialized skin. The area of re-epithelialized skin was measured and analyzed as a percentage of the total wound area. Wound fluid samples were quantitative analysis and expressed as colony forming units.

\section{Measurement amino acids in plasma}

The levels of arginine, citrulline and ornithine concentrations in plasma were determined using a fully automated HPLC system as described previously (Van Eijk et al., 1994).

\section{Statistical analysis}

All data are expressed as mean \pm standard deviation and repeated-measures ANOVA was used to compare both groups. $\quad \mathrm{P}<0.05$ was considered statistically significant.

\section{Results}

\section{Patient characteristics}

Nine patients (male/female: 6/3) were selected into arginine group and 10 patients were selected into control group (Table I). In arginine group, age average was 43.1 years, weight average was $80.9 \mathrm{~kg}$, BMI was $26.3 \mathrm{~kg} / \mathrm{cm}^{2}$, CRP average was $12.6 \mathrm{mg} / \mathrm{L}$, albumin average was $32.5 \mathrm{~g} / \mathrm{L}$ and total plasma protein was 67.7 $\mathrm{g} / \mathrm{L}$ (Table I). In control group, age average was 43.5 years, weight average was $81.3 \mathrm{~kg}$, BMI was $26.8 \mathrm{~kg} /$ $\mathrm{cm}^{2}$, CRP average was $12.9 \mathrm{mg} / \mathrm{L}$, albumin average was $31.6 \mathrm{~g} / \mathrm{L} \&$ total plasma protein was $65.9 \mathrm{~g} / \mathrm{L}$ (Table I).

\section{Table I}

\begin{tabular}{|lcc|}
\hline \multicolumn{3}{|c|}{ Characteristics of patient } \\
\hline & $\begin{array}{c}\text { Arginine } \\
(\mathrm{n}=9)\end{array}$ & $\begin{array}{c}\text { Control } \\
(\mathrm{n}=10)\end{array}$ \\
\hline Age (years) & 43.1 & 43.5 \\
Male/female & $6 / 3$ & $5 / 5$ \\
Weight $(\mathrm{kg})$ & 80.9 & 81.3 \\
BMI (kg/cm $\left.{ }^{2}\right)$ & 26.3 & 26.8 \\
CRP (mg/L) & 12.6 & 12.9 \\
Albumin (g/L) & 32.5 & 31.6 \\
Total plasma protein (g/L) & 67.7 & 65.9 \\
\hline
\end{tabular}

\section{Characteristic of operations}

Reason for operation of arginine group was burns (1 patient), trauma (6 patients), malignancy (3 patients) and other reason ( 3 patients) (Table II). Reason for operation of arginine group was burns (1 patient), trauma (5 patients), malignancy ( 1 patient) and other reason (4 patients) (Table II).

\begin{tabular}{|c|c|c|}
\hline \multicolumn{3}{|c|}{ Table II } \\
\hline \multicolumn{3}{|c|}{ Characteristic of operations } \\
\hline Reason for operation & $\begin{array}{l}\text { Arginine } \\
(\mathrm{n}=9)\end{array}$ & $\begin{array}{l}\text { Control } \\
(\mathrm{n}=10)\end{array}$ \\
\hline Burns & 1 & 1 \\
\hline Trauma & 6 & 5 \\
\hline Malignancy & 3 & 1 \\
\hline Other & 3 & 4 \\
\hline \multicolumn{3}{|l|}{ Type of operation } \\
\hline Split skin graft & 8 & 6 \\
\hline $\begin{array}{l}\text { Muscle transposition }+ \\
\text { split skin graft }\end{array}$ & 1 & 1 \\
\hline $\begin{array}{l}\text { Split skin graft }+ \text { split } \\
\text { skin graft }\end{array}$ & 3 & 5 \\
\hline
\end{tabular}

\section{Plasma amino acids}

Plasma arginine and ornithine concentrations of supplementation with arginine group were higher than those of control group (Figure 1A-B). Especially, plasma arginine and ornithine concentrations in arginine group were the highest after arginine-treated at 2 days (Figure 1A-B). Meanwhile, when arginine-treated at 5 days, plasma arginine and ornithine concentrations in arginine group were higher (Figure 1A-B). But, there were no significance in plasma citrulline and sumAA concentrations of arginine group or control group (Figure 1CD). In control group, plasma alanine concentrations begin to increase and peaked at 2 days after argininetreated, comparison with control group (Figure 1E).

\section{Evaluation of wound healing}

There were no significance in number of PMN/HPF, vessels and percentage of the total wound area of arginine group or control group (Figure 2A-C).

\section{Discussion}

Arginine is a substrate of NO synthesis, it can synthesis a large number of $\mathrm{NO}$ under the actions of $\mathrm{NO}$ synthase (Morris and Labhasetwar, 2015). It is a kind of gas molecules with functions to inhibit the proliferation of smooth muscle cell (Wang et al., 2014). In our study, plasma arginine and ornithine concentrations in arginine 


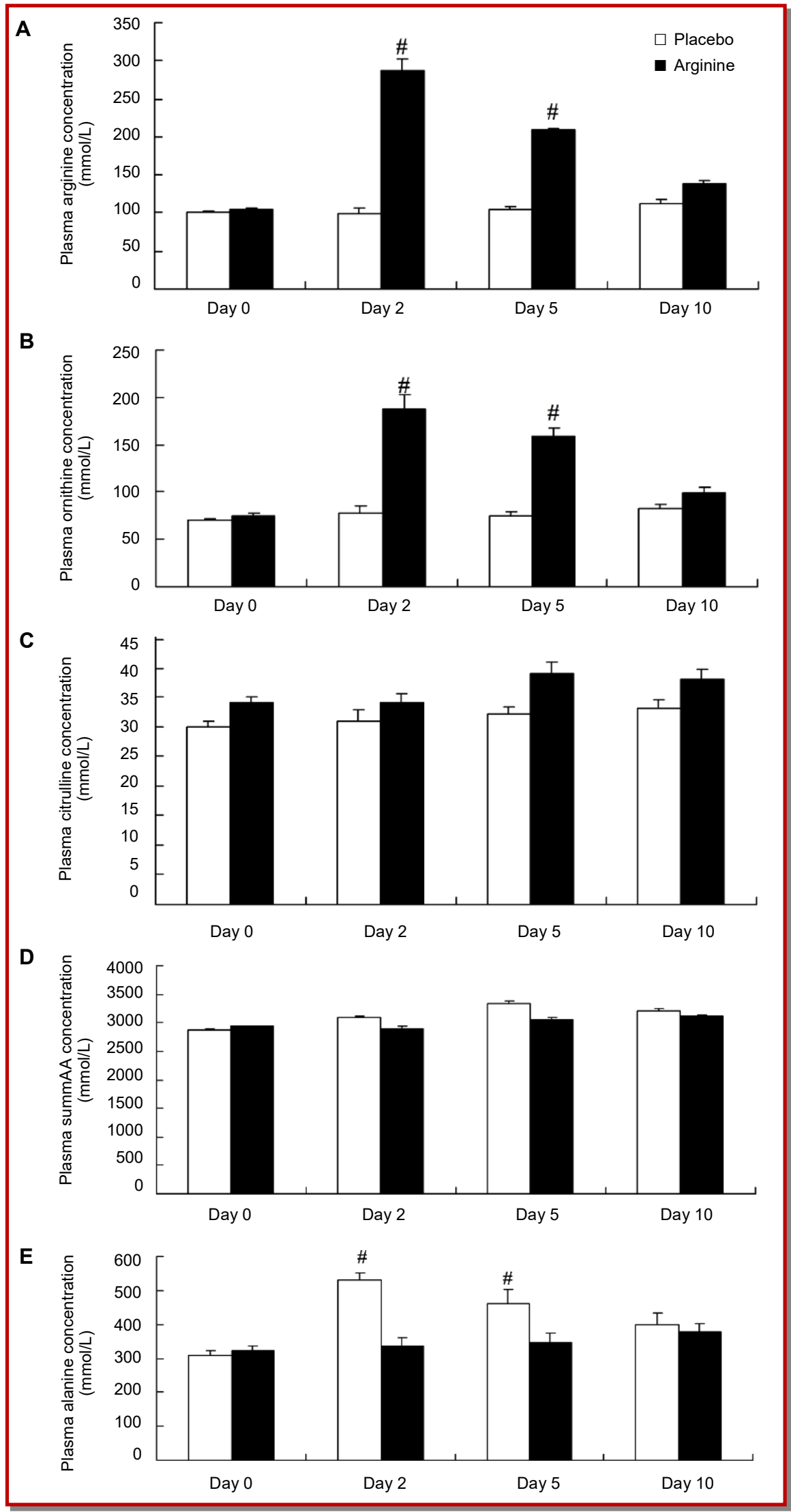

Figure 1: Plasma arginine (A), ornithine (B), citrulline (C), sumAA (D), and alanine (E) concentrations; " $\mathrm{p}<0.05$ compared with 0 day 


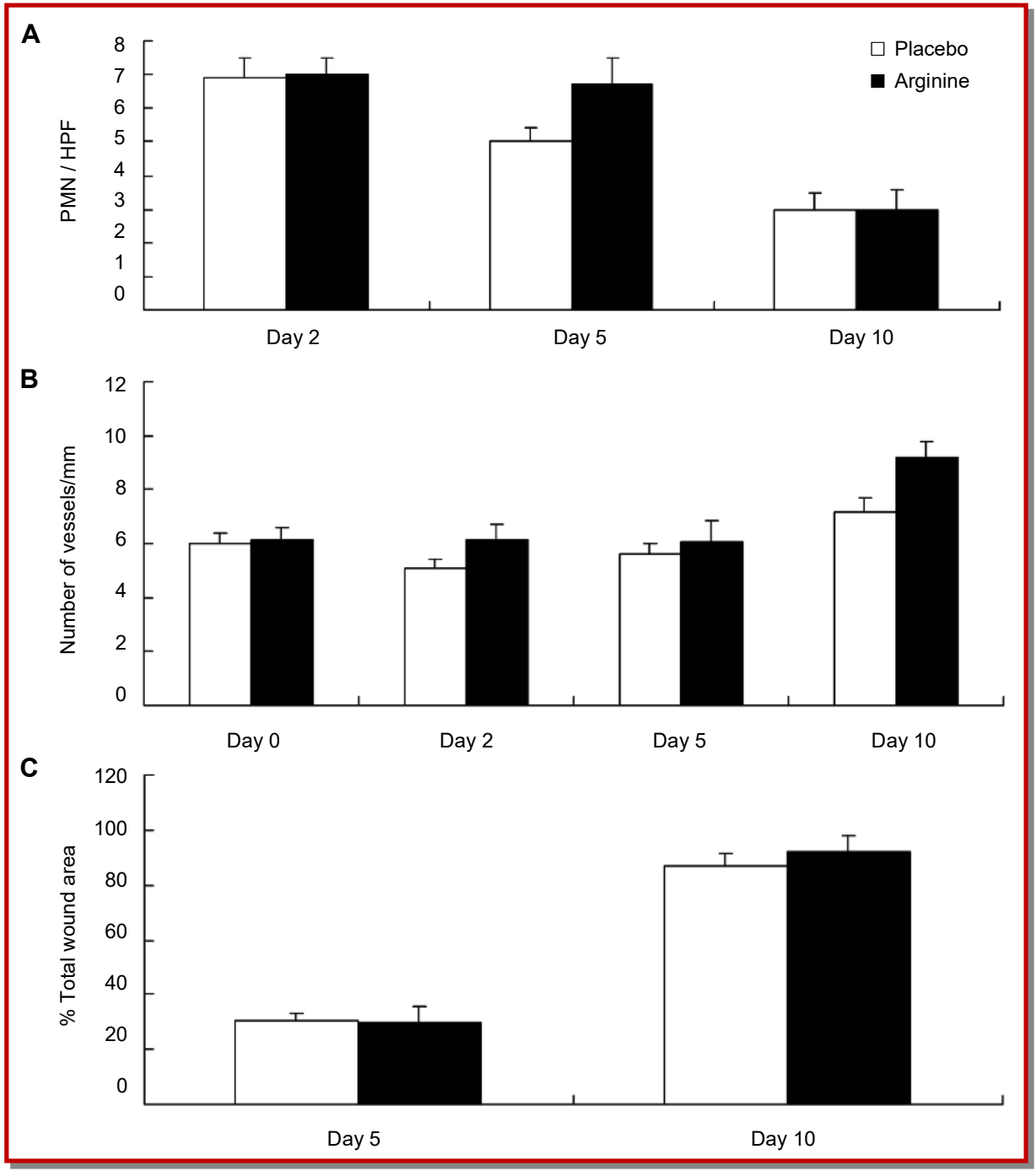

Figure 2: Evaluation of wound healing

group were the highest after arginine-treated at 2 days.

Arginine is the physiological precursor of $\mathrm{NO}$, and it forms $\mathrm{NO}$ after catalyzed by $\mathrm{NO}$ synthase (Ognibene et al., 2010). Exogenous arginine is one of the ways to enhance the content of NO (Yurkiv et al., 2015). Presently, it has been reported in the literature at home and abroad that arginine has protective effects towards different skin graft, and its protective effects towards flap is accomplished by means of following mechanisms: Exogenous arginine becomes the source of $\mathrm{NO}$ after catalyzed by NO synthase inside body, and the increased NO content in skin tissue can play its positive role: firstly, to improve flap microcirculation: content of endothelin has increased in skin tissue after skin flap forming, the corresponding increased NO can reduce the vessel contraction effect and improve blood stream state.

Through CGMP, NO decreased platelet aggregation rate, inhibited the formation of thrombus, reduced resistance of blood flow and improved microcirculation of the flap
(Ozyazgan et al., 2007; Debats et al., 2009; Debats et al., 2011; Afraz et al., 2012). Secondly, to inhibit the injury of leukocyte mediated: foreign scholars found in the study of skin graft that after lifting the flaps, inflammatory cells increased including leukocyte and mastocyte, which mainly increased white blood cells. NO can inhibit the injury by inhibiting leukocyte-adhesion and aggregation. But, there were no significance in plasma arginine and ornithine concentrations, number of PMN/ $\mathrm{HPF}$, vessels and percentage of the total wound area of arginine group or control group. Supplementation of intravenous arginine could not affect on healing of human skin graft donor sites, improve angiogenesis, reepithelialization or neutrophil influx in rats.

\section{Ethical Issue}

The study protocol was endorsed by the Medical Ethical Committee of the Hospital; besides, each participant provided informed consent. 


\section{Acknowledgement}

This work was supported by Suzhou Science and Technology Development Planning Project (SYSD2012091) and Young Workers Research of The Second Affiliated Hospital of Soochow University (SDFEYQN1308).

\section{References}

Afraz S, Kamran A, Moazzami K, Nezami BG, Dehpour AR. Protective effect of pharmacologic preconditioning with pioglitazone on random-pattern skin flap in rat is mediated by nitric oxide system. J Surg Res. 2012; 176: 696-700.

Baeten CI, Wagstaff J, Verhoeven IC, Hillen HF, Griffioen AW. Flow cytometric quantification of tumour endothelial cells: An objective alternative for microvessel density assessment. Br J Cancer. 2002; 87: 344-47.

Davidson A, Jina NH, Marsh C, Than M, Simcock JW. Do functional keratin dressings accelerate epithelialization in human partial thickness wounds? A randomized controlled trial on skin graft donor sites. Eplasty 2013; 13: e45.

Debats IB, Booi DI, Wehrens KM, Cleutjens J, Deutz NE, van de Hogen E, Bemelmans M, van der Hulst RR. Oral arginine supplementation and the effect on skin graft donor sites: A randomized clinical pilot study. J Burn Care Res. 2009; 30: 417-26.

Debats IB, Koeneman MM, Booi DI, Bekers O, van der Hulst RR. Intravenous arginine and human skin graft donor site healing: A randomized controlled trial. Burns 2011; 37: 42026.

Dornseifer U, Lonic D, Gerstung TI, Herter F, Fichter AM, Holm C, Schuster T, Ninkovic M. The ideal split-thickness skin graft donor-site dressing: A clinical comparative trial of a modified polyurethane dressing and aquacel. Plast Reconstr Surg. 2011; 128: 918-24.

Greenwood JE, Dearman BL. Split skin graft application over an integrating, biodegradable temporizing polymer matrix: Immediate and delayed. J Burn Care Res. 2012; 33: 7-19.

Karlsson M, Lindgren M, Jarnhed-Andersson I, Tarpila E. Dressing the split-thickness skin graft donor site: A randomized clinical trial. Adv Skin Wound Care. 2014; 27: 20-25.

Kim SW, Choi SH, Kim JT, Kim YH. An additional option for split-thickness skin graft donors: The previous free flap sites. Ann Plast Surg. 2015.

Lindford A, Saarinen P, Vuola J. Plication technique for thick split-thickness skin graft donor sites. J Plast Reconstr Aesthet Surg. 2011; 64: e187-88.

Morris VB, Labhasetwar V. Arginine-rich polyplexes for gene delivery to neuronal cells. Biomaterials 2015; 60: 151-60.

Nakase I, Konishi Y, Ueda M, Saji H, Futaki S. Accumulation of arginine-rich cell-penetrating peptides in tumors and the potential for anticancer drug delivery in vivo. J Control Release. 2012; 159: 181-88.

Ognibene DT, Moss MB, Matsuura C, Brunini TM, de Moura RS, Mendes-Ribeiro AC, Resende AC. Characterization of the L-arginine-NO-cGMP pathway in spontaneously hypertensive rat platelets: The effects of pregnancy. Hypertens Res. 2010; 33: 899-904.

Ozyazgan I, Ozkose M, Baskol G. Nitric oxide in flow-through venous flaps and effects of L-arginine and nitro-L-arginine methyl ester (L-NAME) on nitric oxide and flap survival in rabbits. Ann Plast Surg. 2007; 59: 550-57.

Raza MS, Nazim T, Khan FA. Comparison of bupivacaine moistened dressing and conventional dressing for pain relief on skin graft donor sites. J Coll Physicians Surg Pak. 2014; 24: 416-19.

Read JM, Bach PH. Sterile topical lignocaine jelly in plastic surgery: An assessment of its systemic toxicity. S Afr Med J. 1980; 57: 704-06.

Roche-Kubler B, Monnin C, Aubin F, Dupond AS. Erosive pustular dermatosis of the scalp and thigh associated with skin graft recipient and donor sites. Eur J Dermatol. 2015.

Takabayashi Y, Ishihara M, Sumi Y, Takikawa M, Nakamura S, Kiyosawa T. Platelet-rich plasma-containing fragminprotamine micro-nanoparticles promote epithelialization and angiogenesis in split-thickness skin graft donor sites. J Surg Res. 2015; 193: 483-91.

Tam J, Wang Y, Farinelli WA, Jimenez-Lozano J, Franco W, Sakamoto FH, Cheung EJ, Purschke M, Doukas AG, Anderson RR. Fractional skin harvesting: Autologous skin grafting without donor-site morbidity. Plast Reconstr Surg Glob Open. 2013; 1: e47.

Van Eijk HM, Dejong CH, Deutz NE, Soeters PB. Influence of storage conditions on normal plasma amino-acid concentrations. Clin Nutr. 1994; 13: 374-80.

Wang XP, Zhang W, Liu XQ, Wang WK, Yan F, Dong WQ, Zhang Y, Zhang MX. Arginase I enhances atherosclerotic plaque stabilization by inhibiting inflammation and promoting smooth muscle cell proliferation. Eur Heart J. 2014; 35: 911-19.

Wu FL, Yeh TH, Chen YL, Chiu YC, Cheng JC, Wei MF, Shen LJ. Intracellular delivery of recombinant arginine deiminase (rADI) by heparin-binding hemagglutinin adhesion peptide restores sensitivity in rADI-resistant cancer cells. Mol Pharm. 2014; 11: 2777-86.

Yurkiv B, Wasser SP, Nevo E, Sybirna NO. The effect of Agaricus brasiliensis and Ganoderma lucidum medicinal mushroom administration on the L-arginine/nitric oxide system and rat leukocyte apoptosis in experimental type 1 diabetes mellitus. Int J Med Mushrooms. 2015; 17: 339-50.

\footnotetext{
Author Info

, Ke Li (Principal contact)

e-mail: xiaoyuzhao123@yeah.net; Tel and Fax: +86-0512-67780113

First three authors contributed equally
} 